\title{
Prevalence of Neurological Disorders in Bangalore, India: A Community-Based Study with a Comparison between Urban and Rural Areas
}

\author{
M. Gourie-Devia ${ }^{\text {G. Gururaj }}{ }^{\text {b }}$ P. Satishchandra ${ }^{a}$ D.K. Subbakrishna ${ }^{c}$ \\ Departments of aNeurology, ${ }^{b}$ Epidemiology and ${ }^{\mathrm{C} B i o s t a t i s t i c s, ~ N a t i o n a l ~ I n s t i t u t e ~ o f ~ M e n t a l ~ H e a l t h ~ \& ~ N e u r o s c i e n c e s, ~}$ \\ Bangalore, India
}

\section{Key Words}

Neurological disorders · Neurological services .

Epilepsy $\cdot$ Stroke $\cdot$ India $\cdot$ Bangalore

\begin{abstract}
A population-based neuroepidemiological survey of 102,557 individuals in urban and rural Bangalore in Southern India was conducted to determine the prevalence and pattern of neurological disorders. The study population included subjects from urban $(51,502)$ and rural $(51,055)$ areas, identified through a two-stage stratified random sampling method. Trained social workers administered the screening questionnaire, which had been tested and validated in an earlier pilot study and a neurologist examined the individuals who screened positive. Adults, children ( $<15$ years) and elderly adults ( $>60$ years) constituted 61,34 and $5 \%$ of the study group, respectively. There was a distinct difference in education, occupation and income levels between urban and rural areas with all these parameters being lower in the rural population. In the surveyed population, 3,206 individuals with neurological disorders were detected resulting in crude and age-adjusted prevalence rates of 3,126 and 3,355 per 100,000 population, respectively. The prev-
\end{abstract}

\section{KARGER}

Fax +41613061234

E-Mail karger@karger.ch

www. karger.com
(C) 2004 S. Karger AG, Basel

0251-5350/04/0236-0261\$21.00/0

Accessible online at:

www. karger.com/ned alence rate among children, middle-aged (31-40 years) and elderly adults was $2,653,3,932$ and 5,012 per 100,000 population, respectively. The prevalence of neurological disorders among women $(3,617)$ was higher compared with men $(2,657)$. The prevalence rate in urban and rural populations was 2,190 and 4,070/1,00,000, respectively, implying that neurological disorders were twice as frequent in rural areas as in urban areas. The prevalence rates per 100,000 population of the most frequent disorders in the descending order of frequency were: headache $(1,119)$, epilepsy (883), febrile convulsions (330), cerebrovascular disorder (150), and mental retardation (142). This large-scale population-based survey provides data that will be crucial for developing hospital and community-based neurological services in India and other developing countries.

Copyright $@ 2004$ S. Karger AG, Basel

\section{Introduction}

The sociodemographic and epidemiological transition in developing countries has changed the morbidity and mortality pattern among communities. This has brought non-communicable diseases to the forefront of the health- 
care delivery system. Within this group, neurological disorders constitute a significant proportion affecting morbidity, mortality, disability and quality of life [1, 2]. However, neurological services are slowly expanding in India and, given the vast population, there is an urgent need for reorganization of the services with optimal utilization of existing specialized manpower. In order to plan services in a socioculturally appropriate and cost-effective manner, epidemiological data on neurological diseases form a basic prerequisite. Earlier studies undertaken in India were on a smaller scale and/or involved certain specific ethnic populations [3-5]. Epidemiological studies based on hospital population, geographic isolates, smaller population and focused groups provide valuable information on the pattern of diseases, but do not reflect the true prevalence rates in different communities. Hence, well-designed, population-based studies are crucial for calculating the true prevalence in the communities to plan and organize effective neurological services [6-8]. The present study was undertaken to determine the prevalence and pattern of various neurological disorders in urban and rural areas of Bangalore, through a community-based approach.

\section{Materials and Methods}

The methodology utilized in the present study has been described in detail earlier $[9,10]$ and the salient points are mentioned below. A flow chart depicting the stepwise methods adopted in this study is provided in figure 1 .

The Bangalore district, one of the 23 districts in the state of Karnataka (population: 44,517,398) in South India with a population of $6,489,419$, includes urban and rural population [2]. The district recorded a decennial growth rate of $20.69 \%$ during $1981-1991$. The population of urban Bangalore is 4,823,951, while that of the rural portion is $1,665,468$. The female:male ratio in the district is 903:1,000 and 950:1,000 in urban and rural areas, respectively. The literacy levels are $66 \%$ in urban and $42 \%$ in rural areas [11].

A pilot study was conducted in the city of Bangalore by a twostage study design on an urban population of 3,040 to standardize the methodology. The screening instruments were evaluated for their appropriateness and modifications were made at the end of the study. The sensitivity and specificity of screening questionnaires for children $(<7$ years) was 100 and $99 \%$, respectively, with a positive predictive value of $100 \%$. The questionnaire for adults was found to have a sensitivity, specificity and positive predictive value of 95,98 and $68 \%$, respectively. The methodology for selection of the population, training of the investigators and data collection procedures was evaluated during this pilot study [9].

The Bangalore Urban and Rural Neuroepidemiological (BURN) survey was conducted between January 1, 1993, and September 30, 1995, with the support of a research grant from the Indian Council for Medical Research, New Delhi. The sample size was estimated through standard statistical methods and a population of nearly
100,000 was required to arrive at the true prevalence of neurological disorders, because of the rarity of some neurological disorders. A two-stage stratified random sampling method was adopted to select a population of 50,000 each, in urban and rural areas.

Urban Bangalore can be geographically classified as city municipal limits and urban agglomeration limits. As the boundaries of the latter are ill defined, it was decided to select survey areas within the municipal limits, which were further subdivided into census divisions and census enumeration blocks (CEBs). In the first stage, 10\% of the total (87) divisions were selected on a random basis. In the second stage, $20 \%$ of the CEBs were chosen randomly from each of the 9 divisions. A total of 112 CEBs were identified. Only individuals residing in these blocks for a minimum period of 6 months or more were surveyed to avoid inclusion of migrant population. The total population surveyed was 51,502 .

Rural Bangalore comprises of 8 taluks i.e., Ramanagaram, Devanahalli, Hoskote, Magadi, Kanakapura, Channapatna, Doddaballapur and Nelamangala. The requisite sample of nearly 50,000 individuals was selected, based on the principle of probability proportional to size by a two-stage random sampling method [9]. In the first stage, 4 taluks were identified randomly, based on the proportion of population in each of the taluks with respect to the entire population of the rural district. These were Magadi, Ramanagaram, Doddaballapur and Devanahally taluks. Subsequently, villages from every taluk were stratified into small and large in order to obtain villages with adequate representation of their population sizes. A proportionate population of $9,550,12,450,14,000$ and 14,000 , respectively, from each taluk was identified for the survey. In the second stage, based on population distribution as per size, 20,27, 29 and 26 villages were chosen randomly from the taluks of Devanahalli, Ramanagaram, Magadi and Doddaballapur taluks, respectively. A total of 102 $(13.0 \%)$ villages were selected from 765 villages in rural Bangalore and all households in each of these villages were enumerated and screened.

The survey sites in the urban and rural areas were initially identified using census maps (notional and layout maps) along with the help of local people. The recruited field investigators had previous experience of conducting community health surveys. They were trained, at both the National Institute of Mental Health and Neurosciences and in the field areas, to minimize inter-observer and intraobserver variations. Interviews were conducted in local languages and the head of the household or the surrogate respondent provided information for each family member [12]. The screening instruments consisted of three parts. Part 1 elicited information on sociodemographic characteristics of the households including family composition, age, sex, religion, education, occupation and income. Part 2 of the screening questionnaire included a set of 12 questions to screen individuals $\geq 7$ years of age. Part 3 of the screening questionnaire included a set of 15 questions to screen children $<7$ years of age. As already indicated in our report on the pilot study, the WHO questionnaire was appropriately modified to detect a wider range of neurological disorders [9]. Operational definitions of various neurological disorders were developed at the beginning of the survey to ensure uniform case definition and classification [10]. Individuals who screened positive were examined for the presence or absence of neurological disorders and in $80 \%$ of the situations, domiciliary visits were made by the research team. In the villages, individuals who screened positive were examined at the local health centre or in schools or at their homes. 


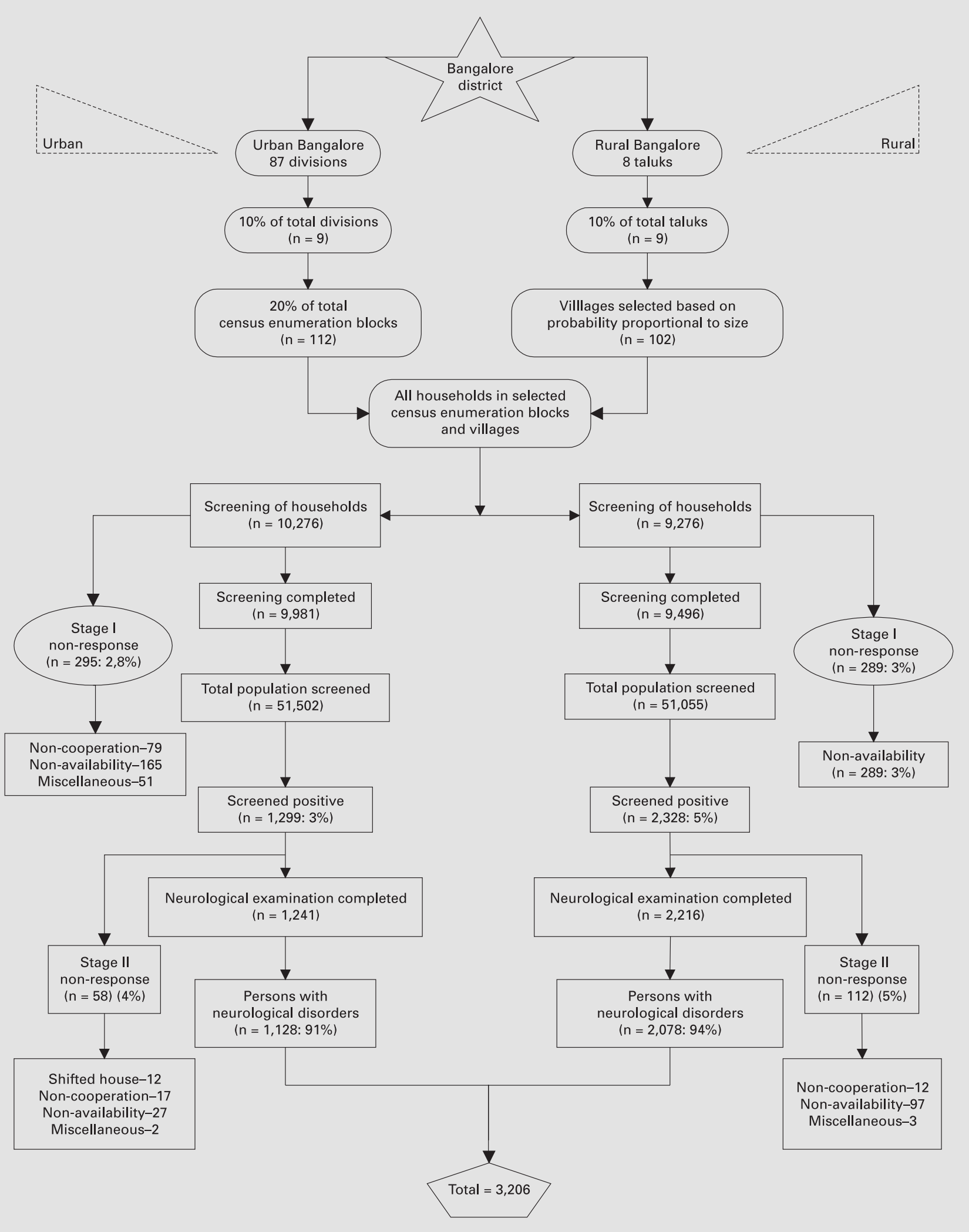

Fig. 1. Methodology of the Bangalore Urban-Rural Neuroepidemiology Survey. 
Table 1. Age and sex distribution in urban and rural population of Bangalore

\begin{tabular}{|c|c|c|c|c|c|c|c|c|c|c|}
\hline \multirow[t]{2}{*}{ Age, years } & \multicolumn{4}{|l|}{ Urban } & \multicolumn{4}{|l|}{ Rural } & \multicolumn{2}{|c|}{ Grand total } \\
\hline & male & female & total & $\%$ & male & female & total & $\%$ & $\mathrm{n}$ & $\%$ \\
\hline $0-5$ & 2,760 & 2,503 & 5,263 & 10.22 & 3,067 & 2,856 & 5,923 & 11.60 & 11,186 & 10.91 \\
\hline $6-10$ & 2,954 & 2,899 & 5,853 & 11.36 & 3,212 & 3,168 & 6,380 & 12.50 & 12,233 & 11.93 \\
\hline $11-15$ & 2,704 & 2,732 & 5,436 & 10.55 & 3,187 & 2,934 & 6,121 & 11.99 & 11,557 & 11.27 \\
\hline $16-20$ & 2,929 & 3,111 & 6,040 & 11.73 & 2,888 & 2,978 & 5,866 & 11.49 & 11,906 & 11.61 \\
\hline $21-30$ & 5,223 & 5,539 & 10,762 & 20.90 & 4,380 & 4,408 & 8,788 & 17.21 & 19,550 & 19.06 \\
\hline $31-40$ & 4,157 & 3,646 & 7,803 & 15.15 & 3,400 & 3,319 & 6,719 & 13.16 & 14,522 & 14.16 \\
\hline $41-50$ & 2,844 & 2,272 & 5,116 & 9.93 & 2,628 & 2,279 & 4,907 & 9.61 & 10,023 & 9.77 \\
\hline $51-60$ & 1,566 & 1,380 & 2,946 & 5.72 & 1,775 & 1,612 & 3,387 & 6.63 & 6,333 & 6.18 \\
\hline $60+$ & 1,194 & 1,089 & 2,283 & 4.43 & 1,531 & 1,433 & 2,964 & 5.81 & 5,247 & 5.12 \\
\hline Total & 26,331 & 25,171 & 51,502 & 100.00 & 26,068 & 24,987 & 51,055 & 100.00 & 102,557 & 100.00 \\
\hline
\end{tabular}

In order to verify the reliability and completeness of information, and to detect false negatives, $10 \%$ of the households who screened negative, selected at random were re-examined by the project team in both urban and rural areas during a resurvey. The survey work was monitored on a day-to-day basis by the monitoring team, comprising of two neurologists and one epidemiologist. Data analysis was carried out using Epi-info (version 6.0) [13].

During the study period, the research team made all efforts to combine 'survey with services to the community'. Patients were provided treatment at the local hospitals and were referred to the National Institute of Mental Health and Neurosciences for further investigations and management whenever necessary.

\section{Results}

During the 2-year period, a total population of 102,572 from 20,061 households was surveyed in urban and rural Bangalore (fig. 1). In urban Bangalore, 112 CEBs from 9 census divisions were enumerated and screened to obtain a total population of 51,502. In rural Bangalore, 102 villages from 4 taluks were surveyed to obtain a population of 51,055. The first stage non-response (at screening level) was 2.8 and $3 \%$ in urban and rural areas, respectively. A total of 3,627 (3.5\%) individuals [urban -1,299 (3\%), rural $-2,328(5 \%)]$ screened positive at this stage. Neurological examination was completed in 3,457 (95.3\%) (urban $-1,241$, rural $-2,216)$ persons, with a second stage non-response rate of 4.7\%. Among them, 3,206 (92.7\%) individuals (urban $-1,128$, rural $-2,078$ ) were confirmed to have one or more neurological disorders.

The age and sex distribution of the population is shown in table 1 . It has been observed that children $(<15$ years) constituted 34.1 and elderly adults (>60 years) $5.1 \%$ of the total population. Children and elderly adults were slightly higher in number in rural areas compared with urban Bangalore (36 vs. $32 \%$ ) and (6 vs. $4 \%$ ), respectively. The male:female ratio in urban and rural areas was 1:0.90 and 1:0.95, respectively.

There was a significant difference in the family composition in urban and rural areas. Medium-size (5-9) and small families ( $<5$ members) comprised 51 and $43 \%$ of the study population, respectively. Households with a family size of $<5$ and 5-9 members were $48 \%$ each, in urban areas, compared with 55 and $40 \%$ in rural areas, respectively. Large-size ( $>10$ members) families were more numerous in rural areas compared with urban areas (6 and 4\%). Among the surveyed population, the populations of Hindus, Muslims and Christians were 87, 9 and $4 \%$, respectively. Individuals with higher education were $14 \%$ in urban areas compared with $1 \%$ in rural areas. Illiterates were $8 \%$ in urban and $37 \%$ in rural areas. The occupational status of the surveyed population revealed that the number of skilled workers was higher in urban areas $(22.5 \%)$ compared with rural areas (5\%). Unskilled workers, predominantly agricultural labourers and landowners, made up nearly $30 \%$ in rural areas. White-collar workers belonging to professional and managerial cadres were $8 \%$ in urban areas, compared with $1 \%$ in rural areas. The household income levels revealed that a significant number of families (95\%) in rural areas had a per capita income of $<$ Rs. 3,000/month. In sharp contrast, nearly $30 \%$ of urban households had a per capita income of $>$ Rs. $3,000 /$ per month.

Table 2 shows the prevalence of neurological disorders in urban and rural Bangalore. During the survey, a total of 3,206 individuals had one or more confirmed neurological disorders, with 228 people (7\%) having more than one 
Table 2. Crude prevalence rates and age adjustment rates (survey population 102,557) in the Bangalore Urban-Rural Neuroepidemiology Survey

\begin{tabular}{|c|c|c|c|c|c|c|c|}
\hline \multirow[t]{2}{*}{ Neurological disorders } & \multicolumn{2}{|l|}{ Urban } & \multicolumn{2}{|l|}{ Rural } & \multirow{2}{*}{$\begin{array}{l}\text { Total No. } \\
\text { of subjects }\end{array}$} & \multirow{2}{*}{$\begin{array}{l}\text { Crude prev- } \\
\text { alence rate } \\
\text { per } 100,000\end{array}$} & \multirow{2}{*}{$\begin{array}{l}\text { Age-adjusted } \\
\text { rate per } \\
100,000\end{array}$} \\
\hline & $\mathrm{n}$ & rate & $\mathrm{n}$ & rate & & & \\
\hline All neurological disorders & 1,128 & 2,190 & 2,078 & 4,070 & 3,206 & 3,126 & 3,355 \\
\hline Epilepsy & 297 & 577 & 609 & 1,193 & 906 & 883 & 826 \\
\hline Febrile convulsion & 102 & 198 & 236 & 462 & 338 & 330 & 261 \\
\hline Headache & 505 & 981 & 643 & 1,259 & 1,148 & 1,119 & 967 \\
\hline Cerebrovascular disorders & 70 & 136 & 84 & 165 & 154 & 150 & 262 \\
\hline Mental retardation & 55 & 107 & 91 & 178 & 146 & 142 & 116 \\
\hline Parkinsonism & 7 & 14 & 21 & 41 & 34 & 33 & 76 \\
\hline Tremors & 29 & 56 & 193 & 378 & 220 & 215 & 408 \\
\hline Facial nerve disorders & 18 & 35 & 45 & 88 & 63 & 61 & 77 \\
\hline Anterior horn cell disorders & 27 & 52 & 86 & 168 & 113 & 110 & 95 \\
\hline Peripheral nerve disorders & 26 & 50 & 43 & 84 & 69 & 67 & 99 \\
\hline Post-encephalitic/meningitic sequelae & 11 & 21 & 26 & 51 & 37 & 36 & 30 \\
\hline
\end{tabular}

neurological disorder. The prevalence rate in urban areas was 2,190 per 100,000 population. In contrast to popular belief, the prevalence of neurological disorders in rural areas was nearly twice as frequent as in urban areas, with a rate of 4,070 per 100,000 people. Thus, it is seen from the above that $3 \%$ of the population is afflicted with neurological disorders in India.

Among the various neurological disorders, vascular headache, epilepsy and tremors were the three major and most frequent disorders with an overall crude prevalence rate of $1,119,883$ and 215 per 100,000 people, respectively. The first two disorders were found to be the most common neurological problems in both urban and rural areas. Cerebrovascular disorders had a total prevalence rate of 150 and it was comparatively higher in rural (165/ $100,000)$ compared with urban areas $(136 / 100,000)$. Similarly, mental retardation (178 vs. 107), anterior horn cell disorders - predominantly post-polio residual paralysis (168 vs. 52 ), peripheral nerve disorders ( 84 vs. 50$)$ and facial nerve disorders ( 88 vs. 35 ) - were more common in rural areas. Parkinson's disease (41 vs. 14) remained high in rural areas, while the prevalence of dementia was similar in both urban and rural populations (14 vs. 12). The number of cases with post-encephalitic/post-meningitic sequelae was again higher in rural areas $(51 / 100,000)$ compared with urban population $(21 / 100,000)$.

The age-specific rates of neurological disorders, shown in table 3, reveal that the highest rates occur among individuals aged $\geq 50$ years, with elderly adults as the most affected group $(5,012 / 100,000)$. It is to be noted that there are 3 peaks with specific reference to particular age groups at periods of $<15,31-40$, and $>60$ years with prevalence rate of $2,653,3,932$ and 5,012 per 100,000 population, respectively. Among children, those aged $\leq 5$ years had the highest rate reaching 3,057/100,000.

The prevalence rates were higher among women $(3,617)$ compared with men $(2,657 / 100,000)$. Further, these rates were also higher in rural areas $(\mathrm{M}: \mathrm{F}$ rates of $3,648: 4,510$ in rural and 1,675:2,729 in urban areas) (table 4).

\section{Discussion}

The present study is the only large-scale, adequatelydesigned, representative, population-based epidemiological study on neurological disorders in India. The study design has overcome the obvious limitations of smaller size samples (their non-representative nature and varying methodologies) using acceptable and standardized screening instruments.

The population surveyed in the earlier studies varied from 14,000 to 60,000 persons $[3-5,14]$. The present study involved more than 100,000 subjects drawn equally from urban and rural areas in a developing country. The age and sex composition of the surveyed population is in accordance with the census data [11]. The sociodemographic characteristics have revealed that people in rural areas have lower levels of education, are predominantly involved with unskilled occupational categories and have 
Table 3. Age-specific prevalence rate of neurological disorders in the Bangalore urban and rural population

\begin{tabular}{|c|c|c|c|c|c|c|c|c|c|}
\hline \multirow[t]{2}{*}{ Age } & \multicolumn{3}{|c|}{ Urban population } & \multicolumn{3}{|c|}{ Rural population } & \multicolumn{3}{|l|}{ Total } \\
\hline & total subjects & s neurol. cases & rate $^{1}$ & total subjects & ts neurol. cases & rate $^{1}$ & total subjects & s neurol. cases & rate $^{1}$ \\
\hline$<15$ & 16,552 & 259 & 1,565 & 18,424 & 669 & 3,631 & 34,976 & 928 & 2,653 \\
\hline $16-20$ & 6,040 & 108 & 1,788 & 5,866 & 173 & 2,949 & 11,906 & 281 & 2,360 \\
\hline $21-30$ & 10,762 & 253 & 2,351 & 8,788 & 323 & 3,675 & 19,550 & 576 & 2,946 \\
\hline $31-40$ & 7,803 & 244 & 3,177 & 6,719 & 327 & 4,867 & 14,522 & 571 & 3,932 \\
\hline $41-50$ & 5,116 & 117 & 2,287 & 4,906 & 222 & 4,524 & 10,023 & 339 & 3,382 \\
\hline $51-60$ & 2,946 & 72 & 2,444 & 3,387 & 176 & 5,196 & 6,333 & 248 & 3,916 \\
\hline $61+$ & 2,283 & 75 & 3,285 & 2,964 & 188 & 6,343 & 5,247 & 262 & 5,012 \\
\hline Total & 51,502 & 1,128 & 2,190 & 51,055 & 2,078 & 4,070 & 102,557 & 3,206 & 3,126 \\
\hline
\end{tabular}

1 Per 100,000 population.

Table 4. Sex-specific prevalence rate of neurological disorders in urban and rural areas

\begin{tabular}{|c|c|c|c|c|c|c|c|}
\hline \multirow{2}{*}{$\begin{array}{l}\text { Area } \\
\text { Sex }\end{array}$} & \multicolumn{2}{|l|}{ Urban } & \multicolumn{2}{|l|}{ Rural } & \multicolumn{2}{|l|}{ Total } & \multirow{2}{*}{$\begin{array}{l}\text { Grand } \\
\text { total }\end{array}$} \\
\hline & male & female & male & female & male & female & \\
\hline Population & 26,331 & 25,171 & 26,068 & 24,987 & 52,399 & 50,158 & 102,557 \\
\hline Disorders & 441 & 687 & 951 & 1,127 & 1,392 & 1,814 & 3,206 \\
\hline Rate/100,000 & 1,675 & 2,729 & 3,648 & 4,510 & 2,657 & 3,617 & 3,126 \\
\hline
\end{tabular}

lower levels of income compared with urban areas. This obviously emphasizes the need for simple screening instruments, adequately trained field investigators in eliciting proper response and providing the necessary supervision. The specific relationship between various neurological disorders, occupation and socioeconomic status needs to be examined with particular reference to aetiopathogenesis, utilization of services and provision of care for neurological disorders.

In terms of methodological issues, the present study has clearly demonstrated that it is possible to conduct population-based neuroepidemiological studies in situations of scarce resources, as reported earlier by Schoenberg [8]. Utilizing adequately trained field investigators for enumeration and screening is a crucial component of this study, since in many developing countries, specialist manpower limitations often hinder researchers from undertaking such studies. Previously published studies from India and other countries have utilized field workers [13, 14], secondary-school graduates [15], medical students $[16,17]$, Anganwadi workers under integrated child de- velopment services [14], non-professional villagers [18], students, teachers and community nurses [19], primary health care workers [20] and even neurologists [17]. While each of these resource groups has its merits and demerits, the choice often depends on the availability of resources in each of the countries. Asking questions and eliciting appropriate responses, often depends upon the adequacy of training and communication skills of interviewers, and should be in local languages [13]. The screening questionnaires have demonstrated that it is possible to detect a wide spectrum of neurological disorders in a community. Neurological disorders are often obvious with clear symptoms and signs and, in the Indian context, the head of the household is in a better position to report presence or absence of symptoms in other members of the family. $\mathrm{He}$ or she is the main responsible person in the family and is fully aware of problems among individual members [12].

The overall prevalence rate of neurological disorders in the community in earlier studies has varied from country to country, ranging from 984 to 4,070 per 100,000 population in India [23] (table 5). Similar observations have $\overline{266} \quad$ Neuroepidemiology 2004;23:261-268
Gourie-Devi/Gururaj/Satishchandra/ Subbakrishna 
Table 5. Prevalence of neurological disorders in India

\begin{tabular}{llllrr}
\hline Author & Year & Place & $\begin{array}{l}\text { Type of } \\
\text { population }\end{array}$ & $\begin{array}{c}\text { Popu- } \\
\text { lation }\end{array}$ & $\begin{array}{l}\text { Prevalence } \\
\text { rate/100,000 }\end{array}$ \\
\hline Gourie-Devi et al. [3] & 1987 & Gouribidanur & rural & 57,660 & 1,382 \\
Bharucha et al. [5] & 1987 & Bombay & urban & 14,010 & 984 \\
Kapoor et al. [14] & 1990 & Ballabgarh (Delhi) & rural & 48,798 & 3,487 \\
Razdan et al. [4] & 1994 & Kuthar Valley (Kashmir) & rural & 63,615 & 967 \\
Gourie-Devi et al. [23] & 1995 & Bangalore & urban & 51,502 & 2,190 \\
Das et al. [18] & \multirow{2}{*}{1996} & Malda & rural & 51,055 & 4,070 \\
& & & rural & 37,286 & 2,856 \\
\hline
\end{tabular}

been made in an African region [20-22]. The difference in prevalence rates may be attributed to varying case definitions and screening instruments along with methods of case ascertainment and classification systems [10]. Two important points have arisen from this study. A higher prevalence rate among children, which may have resulted from childhood epilepsy, infections of the nervous system, post-polio paralysis and febrile convulsions, need further examination. Conversely, higher rates among elderly adults appear to be due to cerebrovascular disorders and degenerative neurological disorders such as Parkinson's disease and dementia. The higher prevalence rate among women compared with men also needs further examination.

With regard to the prevalence rates, it could be summarized that nearly $3 \%$ of the population are suffering from neurological disorders in a developing country like India, based on this large-scale population-based neuroepidemiological survey. Our observations also indicate that in rural areas, these disorders are nearly twice as frequent as in urban areas. Even though there were no demographic differences in the population, and the same screening instruments and examinations were used in urban and rural areas, the prevalence rates were 1-4 times higher in rural areas, a fact attributed to some neurological disorders. Elucidating specific reasons for this difference is beyond the scope of this report and further investigations will be required.

It is more appropriate to establish rational neurological services according to such scientific and valid populationbased epidemiological data rather than on educated estimates [24, 25]. The results of our study have also identified the need for continuously evolving mechanisms of developing epidemiological data through surveillance, and conducting further analytical studies based on a risk factor approach that aims towards prevention. In India,
$70 \%$ of the population lives in rural areas. As our study has shown, the occurrence of neurological diseases in the rural population is twice that in the urban population. Therefore, there is an urgent need to establish the much needed neurology care in the rural sector of India.

\section{Acknowledgement}

The authors are grateful to the Indian Council of Medical Research, New Delhi, India for the financial support in conducting this study. We are also grateful to our colleagues Major R. Varadarajulu, Dr. Javad Ahmed, Dr. H.S. Sathyanarayana, Mr. K. Venkatesh, Mr. J.R. Babu Reddy, Mr. K.P. Puttaswamaiah, Mr. T.G. Srinivas, Mr. Y.N. Rajashekar, Mr. R. Muniyappa, Mr. S.D. Manegar, Mr. L. Vijaya and Mr. Ananda. We are also very thankful to Mr. Vijendra S. Kargudri, for data management and preparing the manuscript. 


\section{References}

1 Chandra V, Pandav CS: The importance of non-communicable diseases in developing countries (editorial). Ind J Com Med 1987;12: 178-180.

2 Gourie-Devi M: Can India afford neuroepidemiology (editorial), Neurol India 1987;35: 125-127.

3 Gourie-Devi M, Rao VN, Prakashi R: Neuroepidemiological study in semi-urban and rural areas in South India: Pattern of neurological disorders including motor neurone disease; in Gourie-Devi M (ed): Motor Neurone Disease: Global Clinical Patterns and International Research. New Delhi, Oxford \& IBH, 1987, pp 11-21.

4 Razdan S, Kaul Rh, Motta A, Kaul S, Bhatt RK: Prevalence and pattern of major neurological disorders in rural Kashmir (India) in 1986. Neuroepidemiology 1994;13:113-119.

$\checkmark 5$ Bharucha NE, Bharucha EP, Dastur HD, Schoenberg BS: Pilot survey of the prevalence of neurologic disorders in the Parsi Community of Bombay, Am J Prev Med 1987;3:293299.

6 WHO study group: The application of advances in Neurosciences for the control of neurological disorders. World Health Organ Tech Rep Ser. Geneva, WHO, 1978, p 629.

7 Kurtzke JF: Neuroepidemiology. Ann Neurol 1984;16:265-277.

8 Schoenberg BS: Clinical neuroepidemiology in developing countries. Neuroepidemiology 1982;1:137-142.

9 Gourie-Devi M, Gururaj G, Satishchandra P, Subbakrishna DK: Neuroepidemiological pilot survey of an urban population in a developing country. A study in Bangalore, South India. Neuroepidemiology 1996;15:313-320.
10 Gourie-Devi M, Gururaj G, Satishchandra P: A Manual for Descriptive Studies: Neuroepidemiology in Developing Countries, ed 2. Bangalore, Prism, 1997.

11 Director of Census operations. Census of India 1991. Karnataka Series II. Government of India, 1991.

12 Gourie-Devi M, Anderson DW, Rao VN: Neuroepidemiologic survey in a developing country: Some questions and answers; in Anderson DW, Schoenberg DG (eds): Neuroepidemiology: A Tribute to Bruce Schoenberg. Boston, CRC, 1991, pp 13-23.

13 Dean AG, Dean JA, Coulombier D, Brendel KA, Smith DC, Burton AH, Dicker RC, Sullivan K, Fagan RF, Arner TG: Epi Info, Version 6: A word processing, database, and statistics program for epidemiology on microcomputers. Atlanta, Centers for Disease Control and Prevention, 1994.

14 Kapoor SK, Chandra V, Banerjee AK, Nath LM, Schoenberg BS: Pilot study of the prevalence of major neurologic disorders in a rural population of India. Neuroepidemiology 1990; 9:287-295.

15 Haimnot RT, Abebe M, Mariam AG, Forsgen L, Heijbel J, Holmgren G, Ekstedt J: Community based study of neurological disorders in rural Central Ethiopia. Neuroepidemiology 1990;9:263-277.

16 Cruz Gutierrez-del-Olmo M, Schoenberg BS, Portera-Sanchez A: Prevalence of neurological diseases in Madrid, Spain. Neuroepidemiology 1989;8:43-47.
17 Meneghini F, Rocca WA, Grigoleno F, et al: Door-to-door prevalence survey of neurological disease in Sicilian population: Background and methods. Neuroepidemiology 1991;10:70_ 85 .

18 Das SK and Sanyal K: Neuroepidemiology of major neurological disorders in rural Bengal. Neurol India 1996;44:47-58.

19 Romdhane NA, Hamida BM, Mrabet A, et al: Prevalence study of neurologic disorders in Kelibia (Tunisia). Neuroepidemiology 1993;12: 285-299.

20 Osuntokun BO, Adeuja AOG, Schoenberg BS et al: Neurological disorders in Nigerian Africans: A community based study. Acta Neurol Scand 1987;75:13-21.

21 Haerer AF, Anderson OW, Schoenberg BS: Prevalence of essential tremor. Results from the Copiah County study. Arch Neurol 1982; 39:750-751.

22 Li SC, Schoenberg BS, Wang CC, et al: Epidemiology of epilepsy in urban areas of the People's Republic of China. Epilepsia 1985;26: 391-394.

23 Gourie-Devi M, Gururaj G, Satishchandra P: Neuroepidemiology in India. A perspective; in Clifford R (ed): Recent Advances in Tropical Neurology. Elsevier, 1995, pp 17-30.

24 Gourie-Devi M, Gururaj G, Satishchandra P Neuroepidemiology in India: Development during three decades. NIMHANS J 1999;17: 279-287.

25 Gourie-Devi M, Gururaj G, Satishchandra P. Epidemiology: Present insights and future prospects. NIMHANS J 1999;17:423-437. 